\title{
PYLORIC STENOSIS IN FOUR FIRST COUSINS
}

\author{
BY \\ C. O. CARTER* and T. R. SAVAGE \\ From The Hospital for Sick Children, Great Ormond Street, London
}

(Received for Publication March 14, 1950)

Although the cause of congenital pyloric stenosis is not known, there is good evidence that one or more genetic factors play a part. This evidence may thus be summarized.

Incidence in Twins. Large series of twin pairs are not yet available for analysis, since it has only recently been realized that the state of the foetal membranes is not a reliable guide to the type of twinning. The reported cases and four additional pairs are discussed by Powell in another paper (page 45). However, it appears that pairs of monozygous twins are more often both affected with pyloric stenosis than are pairs of dizygous twins of like sex, so genetic factors play some part. It is also clear that monozygous twin pairs are not always both affected. Therefore if genes are responsible they do not always manifest themselves.

Incidence in Siblings. Brothers and sisters, other than twins, of children with pyloric stenosis are

\footnotetext{
* In receipt of a grant from the National Birthday Trust Fund.
}

themselves not uncommonly affected. The general incidence in England of pyloric stenosis is probably about 1 in $\mathbf{4 0 0}$ live births. A survey in Newcastle gave the figure of $2 \cdot 8$ per 1,000 live births (Davison, 1946), yet in a survey in which the homes of 212 affected children were visited it was found that at least seven of 324 non-twin siblings had also had the disease (Cockayne and Penrose, 1943).

The incidence in brothers and sisters of affected children is higher than that in the general population. But it is also clear that if a single gene is concerned the rate of manifestation is low.

Incidence in Other Rebtives. Occasional reports of affected pairs of relatives other than siblings have appeared; for example, parent and child (Ashton, 1929) and pairs of first cousins (Cockayne, 1934). But it is not clear that these are more than chance occurrences. If 200 affected children had 1,000 first cousins one would expect to find a few of these affected even if the true incidence among them was

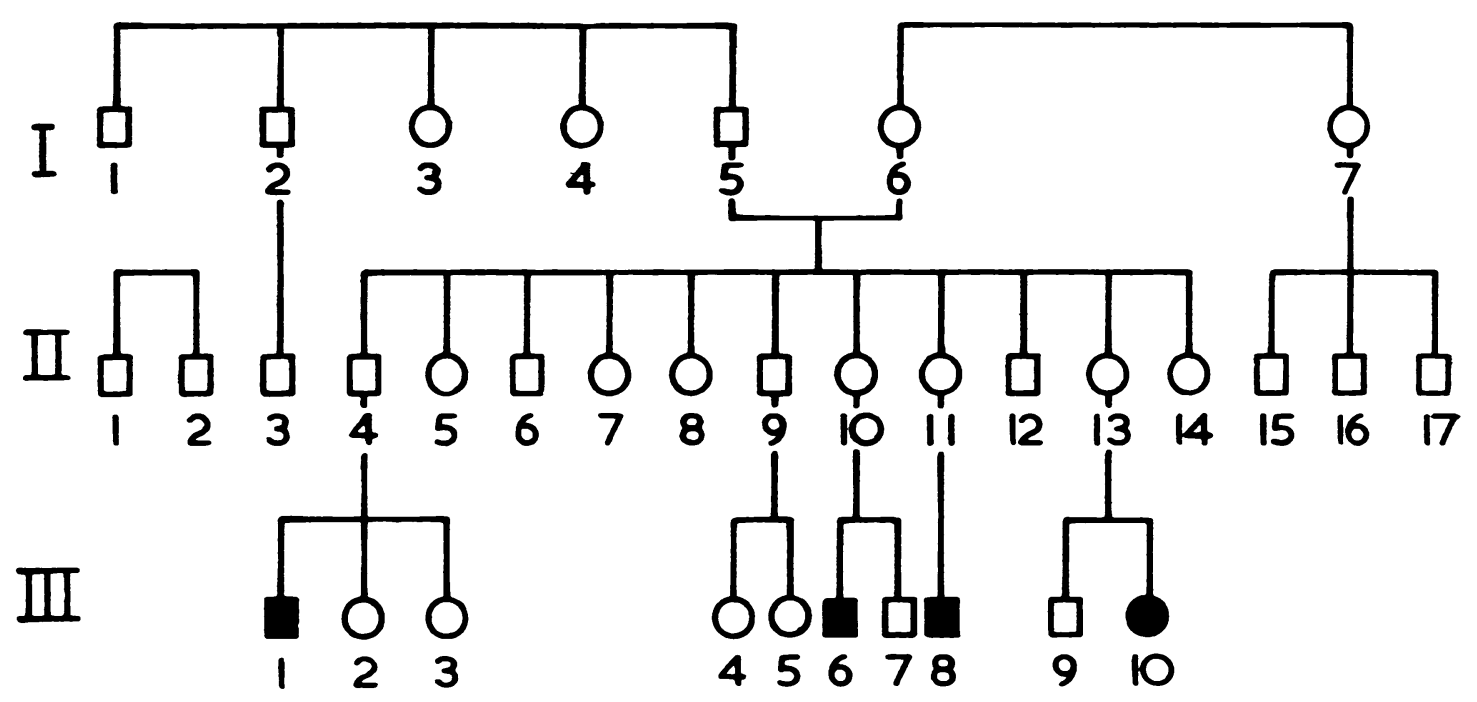

Frg. 1.-Pedigree of the affected family. 
only that of the general population. No surveys have been made which enable us to compare the incidence in parents and first cousins of affected children with the general incidence. At a time when pyloric stenosis was usually lethal one would not expect to find many instances of affected individuals having children. In a series of $\mathbf{4 8 0}$ children treated at The Hospital for Sick Children, Great Ormond Street, London, between 1943 and 1947, it was recorded on two occasions that the father also had the disease. But before very long we should know how often the children of individuals with pyloric stenosis are themselves affected.

\section{Clinical Material}

We have encountered a remarkable family where five of a family of 11 brothers and sisters have had children and four of them have had a child with pyloric stenosis. The condition in each child was diagnosed and confirmed at operation in The Hospital for Sick Children.

The essentials of the family tree are shown in Fig. 1.

In collecting this family tree visits were paid to the homes of the grandparents I 5 and I 6, also of the parents II 4, 10,11, 13, and their spouses. None of the spouses had been affected themselves and none of their near relatives had had an illness suggestive of pyloric stenosis. There were no consanguineous marriages in either parental or grandparental generation.

\section{Discussion}

This family was discovered in the course of a search for examples of twinning and pyloric stenosis. Four hundred and eighty case records were examined. The mother of the fourth child told the physician at the initial interview that she thought that three of her nephews and nieces had been affected.

If the cause of pyloric stenosis were purely environmental it would be an extraordinary coincidence that these four children should be affected. If inherited factors play a part it is a less improbable event, but still remarkable on any simple genetic hypothesis. If a dominant gene were responsible it is surprising that no member of the two preceding generations was affected, whereas if a recessive gene were responsible each of the four brothers and sisters must have married a carrier. At first sight this seems most unlikely, but if the incidence of pyloric stenosis is 1 in $\mathbf{4 0 0}$ and the incidence in siblings of affected children is about 1 in 30 then a high proportion of the population (about 1 in 7) must be carriers on the recessive gene hypothesis.

\section{Summary}

There is evidence that genetic factors play some part in the causation of pyloric stenosis. Identical twins appear to be more often both affected than fraternal twins of like sex, and the incidence in brothers and sisters of children with pyloric stenosis is higher than in the general population.

A family of 11 brothers and sisters is presented. five of whom have had children, and of these four have had a child with pyloric stenosis in which the diagnosis was confirmed at operation.

This family provides additional evidence that genetic factors are in part responsible for the condition. Also it suggests that if a recessive gene of incomplete manifestation is at work then a high proportion of the population must be carriers.

We wish to thank the visiting staff of the hospital for permission to make use of the records of their cases, and also the clerical staff of the follow-up department for their patience in collecting the large numbers of records involved.

\section{REFERENCES}

Ashton, L. O. (1929). Arch. Pediat., 46, 651.

Cockayne, E. A. (1934). Lancet, 1, 898.

, and Penrose, L. S. (1943). Ohio J. Sci., 43, 1.

Davison, G. (1946). Archives of Disease in Childhood, 2i, 113 . 